\title{
TOPSIS Method Based on Entropy Weight for Supplier Evaluation of Power Grid Enterprise
}

\author{
Yanfu Zhang \\ School of Economics and Management \\ North China Electric Power University \\ Beijing, China \\ alwawj@163.com
}

\begin{abstract}
Demand for electric power material has timeliness and effectiveness. To ensure material demands are timely supplied, screening providers need to be cautious. This paper will apply Entropy Weight method and TOPSIS method to building a model for supplier evaluation of Power Grid Enterprise, and verifies by an example.
\end{abstract}

Keywords- entropy weight method; TOPSIS method; Power Grid Enterprise; supplier evaluation

\section{INTRODUCTION}

Supplier evaluation methods are divided into three methods -qualitative method, quantitative method and the combination of first two method. Common quantitative methods including Purchase Cost Comparison method and ABC cost method. The combination of qualitative and quantitative methods including Analysis Hierarchy Process method(AHP), Data Envelopment Analysis method, Fuzzy Comprehensive Analysis method, Gray Correlation Selection Model, Artificial Neural Network method and Fuzzy AHP method etc. [1-2]. Technique for Order Preference by Similarity to an Ideal Solution (TOPSIS ) method sorts programs with ideal and anti-ideal solutions of multi-attribute problems. The method compares the distances between all options and ideal solution and the distances between all options and anti-solution., and the program near ideal solution and far from anti-ideal solution is the most optimal program [3]. Reference [4] determines the evaluation indexes of multimodal transport service provider by analyzing multimodal transport service characteristics, and chooses the best provider utilizing AHP and TOPSIS method. Reference [5] chooses military third party logistics through the combination method of grey relational analysis and TOPSIS method which improves the fairness and reasonableness of the third party logistics selection process. Reference [6] solves the supplier selection problem by combining interval intuitionistic fuzzy sets and TOPSIS method and proves that the decision-making method can work well in supplier selection. Reference [7] establishes hierarchical structure model of power grid supplier evaluation by interviews, and then obtains power grid supplier evaluation index system and its weight through AHP method. Determines the evaluation indexes of multimodal transport service provider by analyzing multimodal transport service characteristics, and chooses the best provider utilizing AHP and TOPSIS method. Reference [8] achieves the integration of qualitative and quantitative supplier evaluation through data envelopment analysis (DEA), which overcomes subjectivity of simple method and realizes objective of supplier evaluation. Reference [9] adds some indexes reflecting green information on the basis of modifying traditional supplier evaluation system, and builds green supplier evaluation model with P-SVM tool. Reference [10] analyzes the influence factors of strategic partner selection from the reality of power grid enterprise, establishes power grid strategic supplier evaluation index system, and proposes power grid strategic supplier evaluation method based on data mining.

\section{PRESENT SITUATION OF SUPPLIER EVALUATION OF POWER GRID ENTERPRISE}

In order to strengthen supplier management, improve equipment and material quality, reduce construction and operation costs, ensure safe and reliable operation of the power grid, power grid enterprises have built a series of assessment standards for supplier evaluation. For example, the suppliers chosen, as well as their products, should accord with these demands as good reputation, good performance, good product quality, good after-sale service, and low operation cost. To sum up on the assessment of two aspects, namely are supplier qualification evaluation and performance evaluation.

Supplier management has played a decisive role for procurement business. From the external market environment, the relationship between enterprises and suppliers has shifted from traditional trading relationship to closer upstream and downstream collaborative relationship in a supply chain. From the internal centralized procurement business of power grid enterprises, supplier management shoulder the responsibility to provide stable high-quality supplier resources to guarantee the supply task while achieving Central Purchasing benefits. Supplier evaluation is an important part of supplier management, and establishing perfect and scientific supplier evaluation system is the key to improve procurement management level of enterprises, as well as an important means to realize the rational allocation of corporate resources and sustainable development. Especially, as a power grid enterprise related to public safety, whether supplier selection is reasonable will directly affect the quality of distribution network engineering, even the entire social demand for electricity. Strengthening the dynamic evaluation and feedback through strengthening the application of the evaluation results, and combining supervision, sampling, supplier and its products during the entire life cycle of production and supplier evaluation work organically, can provide comprehensive 
information for the procurement, and enhance scientific purchasing decision.

\section{MODEL BUILDING}

TOPSIS(Technique for Order Preference by Similarity to an Ideal Solution) method focuses on multi-objective optimization problem, multi-objective optimization problem usually has $m$ evaluation objectives, namely " $D_{1}, D_{2}, \cdots, D_{m}$ ", and each objective has $n$ evaluation indexes, namely “ $X_{1}, X_{2}, \cdots, X_{m}$ ”.

\section{A. Scoring}

First of all, invite relevant experts for evaluation index (qualitative and quantitative indicators) scoring. The scoring results are then expressed in the form of mathematical matrix, and established eigenvalue matrix is as shown in (1):

$$
D=\left[\begin{array}{ccccc}
x_{11} & \cdots & x_{1 j} & \cdots & x_{1 n} \\
\vdots & & \vdots & & \vdots \\
x_{i 1} & \cdots & x_{i j} & \cdots & x_{i n} \\
\vdots & & \vdots & & \vdots \\
x_{m 1} & \cdots & x_{m j} & \cdots & x_{m n}
\end{array}\right]=\left[\begin{array}{c}
D_{1}\left(x_{1}\right) \\
\vdots \\
D_{i}\left(x_{j}\right) \\
\vdots \\
D_{m}\left(x_{n}\right)
\end{array}\right]
$$

\section{B. Standard Matrix Calculation}

The feature matrix is normalized to obtain the normalized vector " $r_{i j}$ ", and build standardized matrix about normalized vector " $r_{i j}$ ". Normalized vector " $r_{i j}$ " is calculated as in (2).

$$
r_{i j}=\frac{x_{i j}}{\sqrt{\sum_{i=1}^{m} x_{i j}^{2}}}, i=1,2, \ldots, m ; j=1,2, \ldots, n \text { (2) }
$$

\section{Index Weight Determining}

Determining the weight of each index through entropy weight method, and the calculation process is as follows.

1) Calculating the proportion " $p_{i j}$ " of index value of project $i$ under index $j$ : “ $p_{i j}$ ” is calculated as in (3).

$$
p_{i j}=\frac{x_{i j}}{\sum_{i=1}^{m} x_{i j}}
$$

2) Calculating the entropy "ej" of index $j$ : “ej" is calculated as in (4).

$$
e_{j}=-k \sum_{i=1}^{m} p_{i j} \cdot \ln p_{i j}
$$

The “ $k$ ” in (4) can be calculated in (5),

$$
k=1 / \ln m \text {. }
$$

3) Calculating the entropy weight "wj" of index $j$ : “wj” is calculated as in (6).

$$
w_{j}=\frac{\left(1-e_{j}\right)}{\sum_{j=1}^{n}\left(1-e_{j}\right)}
$$

4) Building standardized matrix of weight: Calculate standardized value " $v_{i j}$ " of weight and build standardized matrix of weight. " $v_{i j}$ ” is calculated as in (7)

$$
v_{i j}=w_{j} r_{i j}, i=1,2, \ldots, m ; j=1,2, \ldots, n
$$

5) Determining the ideal solution and the anti-ideal solution: Determine the ideal solution " $A$ ", and the anti-ideal solution " $A$ " " according to standardized value " $v_{i j}$ " of weight. " $A$ "” and " $A$ "” are calculated as in (8) and (9).

$$
\begin{aligned}
& A^{*}=\left\{\left(\max _{i} x_{i j} \mid j \in J_{1}\right),\left(\min _{i} v_{i j} \mid j \in J_{2}\right)\right. \\
& ) i=1,2, \cdots, m\}=v_{1}^{*}, v_{2}^{*}, \cdots, v_{n}^{*}(8) \\
& \left.A^{-}=\left\{\left(\min _{i} x_{i j} \mid j \in J_{1}\right),\left(\max _{i} v_{i j} \mid j \in J_{2}\right)\right) i=1,2, \cdots, m\right\}=v_{1},-v_{2}, \cdots, v_{n}^{-}(9)
\end{aligned}
$$

“ $J_{1}$ " in (8) and (9) which represents the most optimal value of index $j$ is a profitability index set; " $J_{2}$ " in (8) and (9) which represents the worst value of index $j$ is a loss index set. " $v_{j}^{*}$ " is the distance between index $j$ and the most optimal objective while " $v$ " is the distance between index $j$ and the worst objective. The larger the profitability index is or the smaller the loss index is, the more favorable to the evaluation result. On the contrary, the more negative to the evaluation result.

6) Calculating distance scale: Distance scale calculated by Euclidean distance is the distance between each objective and ideal solution or anti-ideal solution. " $S$ ", represents the distance between the objective and ideal solution " $A$ ", and " $S$ " represents the distance between the objective and antiideal solution " $A$ "." The calculation formula is as shown in (10) and (11).

$$
\begin{gathered}
S^{*}=\sqrt{\sum_{j=1}^{n}\left(v_{i j}-v_{j}^{*}\right)^{2}} \\
S^{-}=\sqrt{\sum_{j=1}^{n}\left(v_{i j}-v_{j}\right)^{2}}
\end{gathered}
$$

In (10) and (11), “ $i=1,2, \cdots, m$ " and " $S$ "” represents the closeness between each evaluation and the ideal objective. The smaller the value of " $S$ " is, the closer the distance from objective to ideal solution is, and the superior the program is.

7) Calculating closeness degree of ideal solution " $C$ "”: " $C$ "” is calculated as in (12).

$$
C_{i}^{*}=\frac{S_{i}^{-}}{\left(S_{i}^{*}+S_{i}^{-}\right)}, i=1,2, \cdots, m
$$

In (12), " $C_{i}^{*}$ ” is in the range of 0 to 1 , namely [0,1]. When " $C_{i}^{*}=0$ ", then " $A_{i}=A^{*}$ ", which means " $A_{i}$ " is the most optimal evaluation objective. Sorting all the evaluation objectives from 
small to large according to the value of " $C_{i}^{*}$ ". The larger the value of " $C_{i}^{*}$ " is, the better the evaluation objective is.

\section{POWER GRID SUPPLIER EVALUATION SYSTEM}

To choose evaluation indexes and establish index system are important for evaluation analysis of supplier admittance qualification, because it is directly related to whether the result is scientific, objective, accurate and reliable or not, and also related to whether can provide a quantitative and operable basis for power grid enterprises. According to the thought of system theory, to support the method study about supplier qualification evaluation and reflect the qualification level of suppliers scientifically, objectively, fairly and fully, this paper will build observable factor variable index system as the basic support index system for supplier qualification evaluation.

In the supplier selection process, the enterprise needs to take full account of many factors of credit, product, supply ability and others, and the qualitative index and quantitative index should be combined to form a comprehensive and rational supplier evaluation system. As for the aspect of supplier evaluation index selection, scholars design supplier evaluation index mainly from the aspects of supplier management system, supply ability, product quality, price, cost management ability, incentive mechanism, cooperation ability, etc.

In accordance with the principles of evaluation index, this paper will obtain 5 first-level indexes of supplier admittance qualification on the basis of present content of qualification evaluation which provide reference for supplier evaluation. The 5 first-level indexes include basic situation, economic, technical, quality management and comprehensive service evaluation index of suppliers. Specific indexes are as shown in Table 1.

\section{EXAMPLE}

A power supply company needs to purchase a number of Intelligent Ammeter. Now select 10 suppliers as evaluation objectives and choose the best of them. The evaluation group determines the value of each index in the supplier evaluation
TABLE I. SUPPLIER EVALUATION INDEX SYSTEM

\begin{tabular}{|c|c|c|c|}
\hline Object Set & $\begin{array}{c}\text { Factor Set } \\
\text { (5 First-level } \\
\text { Indexes) } \\
\end{array}$ & $\begin{array}{c}\text { Sub-factor set } \\
\text { (24 Second-level } \\
\text { Indexes) }\end{array}$ & Index type \\
\hline \multirow{25}{*}{$\begin{array}{c}\text { Supplier } \\
\text { admittance } \\
\text { evaluation }\end{array}$} & \multirow{3}{*}{ Basic Situation } & Financial situation & qualitative \\
\hline & & Credit level & qualitative \\
\hline & & Market share & quantitative \\
\hline & \multirow{8}{*}{$\begin{array}{l}\text { Economic } \\
\text { Evaluation }\end{array}$} & Asset-liability ratio & quantitative \\
\hline & & Return on total assets & quantitative \\
\hline & & Asset turnover & quantitative \\
\hline & & Own funds ratio & quantitative \\
\hline & & Return on equity & quantitative \\
\hline & & Quick ratio & quantitative \\
\hline & & Profit rate & quantitative \\
\hline & & $\begin{array}{c}\text { Economic value } \\
\text { added(EVA) }\end{array}$ & quantitative \\
\hline & \multirow{5}{*}{$\begin{array}{l}\text { Technical } \\
\text { Evaluation }\end{array}$} & Delivery time & quantitative \\
\hline & & Deliveries & quantitative \\
\hline & & $\begin{array}{c}\text { Scientific and technical } \\
\text { personnel }\end{array}$ & quantitative \\
\hline & & $\begin{array}{l}\text { Research funds } \\
\text { investment rate }\end{array}$ & quantitative \\
\hline & & Research conversion rate & quantitative \\
\hline & \multirow{5}{*}{$\begin{array}{c}\text { Quality } \\
\text { Management } \\
\text { Evaluation }\end{array}$} & $\begin{array}{l}\text { Product qualification } \\
\text { ratio }\end{array}$ & quantitative \\
\hline & & $\begin{array}{l}\text { Order change acceptance } \\
\text { rate }\end{array}$ & quantitative \\
\hline & & $\begin{array}{c}\text { Completeness of quality } \\
\text { management system }\end{array}$ & qualitative \\
\hline & & Delivery error rate & quantitative \\
\hline & & Delivery breakage rate & quantitative \\
\hline & \multirow{4}{*}{$\begin{array}{l}\text { Comprehensive } \\
\text { Service Evaluation }\end{array}$} & $\begin{array}{c}\text { Service promise } \\
\text { fulfillment }\end{array}$ & qualitative \\
\hline & & Customer complaint rate & quantitative \\
\hline & & $\begin{array}{l}\text { Customer complaint } \\
\text { handing rate }\end{array}$ & quantitative \\
\hline & & $\begin{array}{l}\text { After-sale service } \\
\text { response time }\end{array}$ & qualitative \\
\hline
\end{tabular}

index system of each supplier according to supplier related data. Qualitative indexes are scored by evaluation group, and the score ranges from 0 to 10. Quantitative index data derive from raw data or calculation. Supplier index data are detailed in table I

TABLE II. SUPPLIER INDEX INTIAL DATA

\begin{tabular}{|c|c|c|c|c|c|c|c|c|c|c|}
\hline \multirow{2}{*}{ Index } & \multicolumn{10}{|c|}{ Supplier } \\
\hline & $N_{1}$ & $\mathrm{~N}_{2}$ & $N_{3}$ & $N_{4}$ & $N_{5}$ & $N_{6}$ & $N_{7}$ & $N_{8}$ & $N_{9}$ & $N_{10}$ \\
\hline Quality $\left(\mathrm{C}_{1}\right)$ & 9 & 8 & 7 & 6 & 8 & 8 & 9 & 8 & 7 & 10 \\
\hline $\begin{array}{c}\text { Product Qualification } \\
\text { Ratio }\left(\mathrm{C}_{2}\right)\end{array}$ & 0.94 & 0.93 & 0.91 & 0.92 & 0.94 & 0.93 & 0.97 & 0.96 & 0.92 & 0.99 \\
\hline Rework Return Rate $\left(\mathrm{C}_{3}\right)$ & 0.08 & 0.11 & 0.12 & 0.17 & 0.12 & 0.14 & 0.09 & 0.07 & 0.20 & 0.03 \\
\hline Price Ratio( $\left(\mathrm{C}_{4}\right)$ & 1.102 & 1.002 & 0.840 & 1.042 & 1.002 & 0.902 & 1.042 & 1.122 & 0.962 & 0.982 \\
\hline $\begin{array}{l}\text { Restocking Fee Savings } \\
\text { Rate }\left(\mathrm{C}_{5}\right)\end{array}$ & 1.10 & 1.01 & 0.87 & 1.01 & 0.99 & 0.92 & 1.07 & 1.01 & 0.99 & 0.96 \\
\hline $\begin{array}{c}\text { Factory Inspection } \\
\text { Qualification Ratio }\left(\mathrm{C}_{6}\right) \\
\end{array}$ & 0.98 & 0.95 & 0.92 & 0.95 & 0.93 & 0.94 & 0.98 & 0.95 & 0.93 & 0.98 \\
\hline $\begin{array}{l}\text { Equipment Failure } \\
\text { Rate }\left(C_{7}\right)\end{array}$ & 0.03 & 0.05 & 0.05 & 0.08 & 0.04 & 0.05 & 0.02 & 0.04 & 0.07 & 0.01 \\
\hline $\begin{array}{c}\text { Average Service } \\
\text { Response Time (day) }\left(\mathrm{C}_{8}\right)\end{array}$ & 13 & 10 & 8 & 6 & 9 & 8 & 5 & 7 & 6 & 6 \\
\hline $\begin{array}{c}\text { Production Plan } \\
\text { Timeliness rate }\left(\mathrm{C}_{9}\right)\end{array}$ & 0.8 & 0.82 & 0.78 & 0.75 & 0.8 & 0.7 & 0.9 & 0.8 & 0.82 & 0.95 \\
\hline $\begin{array}{c}\text { Production Plan } \\
\text { Punctuality Rate }\left(\mathrm{C}_{10}\right)\end{array}$ & 0.82 & 0.78 & 0.82 & 0.60 & 0.75 & 0.67 & 0.79 & 0.85 & 0.88 & 0.88 \\
\hline
\end{tabular}




\begin{tabular}{|c|c|c|c|c|c|c|c|c|c|c|}
\hline $\begin{array}{c}\text { Production Information } \\
\text { Submitted Timeliness } \\
\text { Rate }\left(\mathrm{C}_{11}\right)\end{array}$ & 0.94 & 0.88 & 0.92 & 0.95 & 0.96 & 0.89 & 0.91 & 0.95 & 0.90 & 0.98 \\
\hline $\begin{array}{c}\text { Production Information } \\
\text { Submitted Punctuality } \\
\text { Rate }\left(\mathrm{C}_{12}\right)\end{array}$ & 0.97 & 0.96 & 0.97 & 0.92 & 0.95 & 0.95 & 0.97 & 0.92 & 0.94 & 0.95 \\
\hline Cooperation Degree $\left(\mathrm{C}_{13}\right)$ & 7 & 8 & 9 & 6 & 10 & 9 & 10 & 9 & 8 & 9 \\
\hline
\end{tabular}

\section{CONCLUSION}

(1) Establish eigenvalue matrix, and calculate the matrix's standardized " $R$ ” matrix (10 evaluation objectives, 13 evaluation indexes) with (2). Then, determine the weight " $w_{j}$ " of each index through entropy weight method. The weight vector " $W$ " is as follows:

$W=(0.0336,0.0011,0.3264,0.0119,0.0072,0.0009,0.4028$, $0.1421,0.0119,0.0221,0.0020,0.0006,0.0372$ )

(2) Calculate normalized weight and establish normalized matrix, according to which determine the ideal solution " $A$ ", and anti-ideal solution " $A$ "”. " $A$ ", and " $A$ "” are shown as follows:

\section{$A^{*}=1.0 e-3$}

$(13.2,0.4,168.7,4.2,2.5,0.3,210.7,71.9,4.4,7.8,0.7,0.2,13.7)$ $A^{-}=1.0 e-3$

(7.9,0.3,25.3,3.1,2.0,0.3,26.3,27.7,3.2,5.3,0.6,0.2,8.2)

(3) Calculate the distance " $S$ ", between the objective and ideal solution " $A$ ", and the distance " $S$ ", between the objective and anti-ideal solution " $A$ ". " $S$ " , and " $S$ " are shown as follows:

$S^{*}=(0.166,0.111,0.108,0.047,0.127,0.098,0.189,0.156,0.047$,

$S^{*}=(0.081,0.128,0.131,0.219,0.112,0.141,0.058,0.087,0.213$, 0.009)

(4) Calculate the closeness degree " $C^{*}$ " of ideal solution. The closeness degree of each supplier is shown as table 2.

TABLE III. CLOSENESS OF EACH SUPPLIER

\begin{tabular}{|c|c|c|c|c|}
\hline Supplier $(\boldsymbol{j})$ & $\boldsymbol{S}_{\boldsymbol{j}}{ }^{*}$ & $\boldsymbol{S}_{\boldsymbol{j}}$ & $\boldsymbol{C}_{\boldsymbol{j}}{ }^{*}$ & Sorting result \\
\hline 1 & 0.166 & 0.081 & 0.327 & 8 \\
\hline 2 & 0.111 & 0.128 & 0.536 & 5 \\
\hline 3 & 0.108 & 0.131 & 0.549 & 4 \\
\hline 4 & 0.047 & 0.219 & 0.823 & 1 \\
\hline 5 & 0.127 & 0.112 & 0.468 & 6 \\
\hline 6 & 0.098 & 0.141 & 0.591 & 3 \\
\hline 7 & 0.189 & 0.057 & 0.234 & 9 \\
\hline 8 & 0.156 & 0.087 & 0.358 & 7 \\
\hline 9 & 0.047 & 0.213 & 0.819 & 2 \\
\hline 10 & 0.237 & 0.009 & 0.037 & 10 \\
\hline
\end{tabular}

As can be seen from the table II, the values of " $C_{4}{ }^{*}$ ” and " $C_{9}{ }^{*}$ " are respectively 0.823 and 0.819 which are the largest two among the 10 closeness degrees while the value of " $C_{10}{ }^{*}$ " is the smallest. The result illustrates that supplier 4 is the best selection.
The paper mainly aims at the question of power grid supplier evaluation through the combination method of TOPSIS method and entropy weight method, which can provides power grid enterprises with reliable means to choose suppliers. The combination of the two methods in the paper makes evaluation result more rational and persuasive for their complementary advantages that can well assist in supplier selection decision-making for power grid enterprises.

\section{REFERENCES}

[1] Chuanyong Yin, "Supplier selection methods and their comparison," Legal System and Society, 2007, pp.306-307.

[2] Hao Wang, “A review of supplier selection method," Logistics SciTech, 2012, pp.87-89.

[3] Jianru Su and Xiaolin Li, "Supplier selection research analysis," the Tenth Annual Conference Proceedings Beijing Higher Education Research Association of Technical Equipment, 2008, pp.73-77.

[4] Qiang Gao and Jinfu Zhu, “Application of hybrid TOPSIS method in multimodal service selection,” Logistics Sci-Tech, 2008, pp.11-14.

[5] Shaoxiong Peng, "Military third party logistics supplier evaluation analysis based on TOPSIS method and grey correlation method," Logistics Sci-Tech, 2012, pp.83-87.

[6] Lei Wen, Rui Wang and Wei Zhao, "Supplier selection based on interval valued intuitionistic fuzzy set TOPSIS method," Logistics Sci-Tech, 2012, pp.23-26.

[7] Bo Luo, "Power grid supplier evaluation system establishment method based on AHP method,” Sun Yatsen University Forum, vol 27, 2007, pp.287-291.

[8] Wei Yuan and Desheng Li, "Reserch on supplier evaluation method based on DEA,” Way of Success, 2007, pp.55-56.

[9] Xuesong Guo, Linyan Sun and Sheng Xu, "Green supplier evaluation mdel based on P-SVW,” Forecasting, 2007, pp.7-11.

[10] Bin Song, Chunhui Liu, Yanli Zhao and Hongqing Zhang, "Srategic supplier evaluation for power grid enterprises based on data mining," Logistics Technology, 2014, pp.444-447. 